\title{
The effects of intravenous lignocaine on depth of anaesthesia and intraoperative haemodynamics during open radical prostatectomy
}

\author{
Laurence Weinberg ${ }^{1,2^{*}}$, Jae Jang ${ }^{3}$, Clive Rachbuch ${ }^{4}$, Chong Tan $^{2}$, Raymond $\mathrm{Hu}^{2}$ and Larry McNicol${ }^{2}$
}

\begin{abstract}
Background: Lignocaine is a local anaesthetic agent, which is also commonly used as a perioperative analgesic adjunct to accelerate rehabilitation and enhance recovery after surgery. Lignocaine's systemic effects on intraoperative haemodynamics and volatile anaesthetic requirements are not well explored. Therefore, we evaluated the effects of intravenous lignocaine on intraoperative volatile agent requirements and haemodynamics in patients undergoing major abdominal surgery.
\end{abstract}

Methods: We performed an analysis of 76 participants who underwent elective open radical retropubic prostatectomy. Patients received lignocaine $(1.5 \mathrm{mg} / \mathrm{kg}$ loading dose) followed by an infusion $(1.5 \mathrm{mg} / \mathrm{kg} / \mathrm{h})$ for the duration of surgery, or saline at an equivalent rate. The aims of the study were to evaluate the end-tidal sevoflurane concentration required to maintain a bispectral index of between 40 and 60 . Measurements included intraoperative blood pressure, heart rate, and the volume of intravenous fluids and dosage of vasoactive medications administered.

Results: The average end-tidal sevoflurane concentration was lower in the Lignocaine group compared to saline [1.49\% (SD: 0.32) vs. 1.89\% (SD: 0.29); $95 \%$ Cl 0.26-0.5, p < 0.001]. In the Lignocaine group, the average mean arterial pressure was $80.3 \mathrm{mmHg}$ (SD: 4.9) compared to $85.1 \mathrm{mmHg}$ (SD: 5.4) in the Saline group (95\% Cl 2.4-7.1, p < 0.001). Systolic blood pressure was also lower in the Lignocaine group: $121.7 \mathrm{mmHg}$ (SD: 6.1) vs. $128.0 \mathrm{mmHg}$ (SD: 6.4) in the Saline group; $95 \% \mathrm{Cl} 3.5-9.2, \mathrm{p}<0.001$, as was the mean heart rate [Lignocaine group: 74.9 beats/min (SD: 1.8) vs. 81.5 beats/min (SD: 1.7) in the Saline group, 95\% Cl 4.1-9.1, p < 0.001]. Maintenance fluid requirements were higher in the Lignocaine group: $3281.1 \mathrm{~mL}$ (SD: 1094.6) vs. $2552.6 \mathrm{~mL}$ (SD: 1173.5) in the Saline group, 95\% Cl 206-1251, p=0.007. There were no differences in the use of vasoactive drugs.

Conclusions: Intravenous lignocaine reduces volatile anaesthetic requirements and lowers blood pressure and heart rate in patients undergoing open radical prostatectomy.

Keywords: Lignocaine, Lidocaine, Volatile agents, Depth of anaesthesia, Sevoflurane, Haemodynamics, Blood pressure, Fluids

\section{Background}

Lignocaine is a local anaesthetic agent commonly used as a perioperative analgesic adjunct to accelerate

\footnotetext{
*Correspondence: laurence.weinberg@austin.org.au

${ }^{1}$ Department of Surgery, The University of Melbourne, Austin Health, VIC, Australia

Full list of author information is available at the end of the article
}

rehabilitation and enhance recovery after surgery. In a recent multicentre randomised control trial, we found that the use of intravenous (IV) lignocaine was associated with shorter postoperative hospital stay, reduced pain at rest and reduced 24-h postoperative morphine consumption [1]. However lignocaine's effects on the intraoperative volatile agent requirements and patient haemodynamics have not been consistently 
characterized. Animal studies have shown that the use of IV lignocaine has been associated with a reduction in the minimum alveolar concentration (MAC) of volatile anaesthetic agents [2-5]. However, to date there is limited research evaluating the relationship between IV lignocaine and volatile anaesthetic requirements and intraoperative haemodynamics in patients undergoing major surgery [6-8]. Given this gap in knowledge, we evaluated the effects of lignocaine on the requirement of volatile anaesthetic agents and intraoperative haemodynamics in patients undergoing open radical retropubic prostatectomy.

\section{Methods}

All patients that participated in the original trial by Weinberg et al. [1] who underwent open radical prostatectomy were included in this analysis. In the original multicentre, double-blinded, randomised control study, adult patients over the age of 18 years, and American Society of Anaesthesiologists (ASA) class of I to III were randomly assigned to receive either IV lignocaine (loading dose followed by infusion) or normal saline. The primary outcome of the original study was the length of postoperative hospital stay and secondary outcomes included postoperative pain, analgesia, side effects, and participant satisfaction. However, the effects of IV lignocaine on intraoperative volatile anaesthetic requirements and patient haemodynamics were not reported. The primary aim of this present study is to report the effects of intraoperative IV lignocaine on end-tidal sevoflurane (ET-Sevo) concentration required to maintain a bispectral index of between 40 and 60. In addition, the effects of intraoperative IV lignocaine on blood pressure, heart rate, and volume of fluids, and dosage of vasoactive medications administered are presented.

The original study [1] was approved by Human Research Ethics Units at Austin and Box Hill hospitals (Number: 2008/03180) and registered with the Australian New Zealand Clinical Trials Registry (Number: 12609001073291). All participants provided written consent for the primary study. The Ethics Committee approved the data collection of all the variables reported in this secondary analysis and participant consent was not obtained. For the original study [1], exclusion criteria included laparoscopic surgery, allergy to morphine, nonsteroidal anti-inflammatory drugs, and local anaesthetic agents, cardiac conduction defect, use of class I antiarrhythmic agents or amiodarone, history of seizures, epilepsy, or craniotomy within the last 5 years, myasthenia gravis, cognitive impairment or mental illness, opioid tolerant patients or significant hepatic or renal impairment.

\section{Standardisation of anaesthesia}

All patients had a fasting period of $2 \mathrm{~h}$ for clear fluids and $6 \mathrm{~h}$ for a light meal. There was no preoperative fluid loading. Immediately prior to induction of anaesthesia, the Lignocaine group received IV lignocaine $(1.5 \mathrm{mg} / \mathrm{kg}$ loading dose) over a 3-min period followed by a continuous intraoperative infusion $(1.5 \mathrm{mg} / \mathrm{kg} / \mathrm{h})$. The control group received normal saline at an equal infusion rate. Anaesthesia was induced with IV fentanyl (3 $\mu \mathrm{g} / \mathrm{kg})$, propofol (1-3 $\mathrm{mg} / \mathrm{kg}$ ), and a non-depolarising neuromuscular blocker. Maintenance of anaesthesia was with Sevoflurane, in $50 \%$ oxygen-air balance to maintain a target bispectral index (Aspect Medical $\mathrm{BIS}^{\circledR}$ ) of between 40 and 60. Intraoperative analgesia was standardised with a fentanyl infusion $(2.5 \mu \mathrm{g} / \mathrm{kg} / \mathrm{h})$. Maintenance fluid therapy consisted of a balanced crystalloid $(5 \mathrm{~mL} / \mathrm{kg} / \mathrm{h})$. Additional crystalloid boluses and colloid intervention were administered at the discretion of the treating anaesthetist. Blood transfusion was in accordance with the current Australian patient blood management guidelines [9]. Electrolyte disturbances were managed as per standard medical practice. Core temperature of greater than $36.0{ }^{\circ} \mathrm{C}$ was maintained with warm fluids and a forcedair warming device. Intraoperatively, hypotension was treated with fluid therapy, IV metaraminol (250-500 $\mu \mathrm{g})$ or ephedrine (5-10 mg). Infusion of lignocaine or saline was stopped at the end of the operation on the last surgical stitch.

\section{Types of statistical analysis used}

To analyse the continuous data, Student's t test and Mann-Whitney U tests were performed. To compare means, standard two-sample $t$ tests were used. For categorical data, Chi squared tests were used with the Newcombe-Wilson method to calculate the $95 \%$ confidence interval [10]. p values of $<0.05$ were considered to be of statistical significance.

\section{Results}

Of the 86 participants who consented to participate in the original study [1], nine were planned to undergo laparoscopic prostatectomy and were excluded. In total, 76 patients were eligible. Thirty-eight were assigned to the Lignocaine group and 38 patients were assigned to the Saline group. One patient from the Lignocaine group had his operation cancelled due to anaphylaxis caused by cefazolin. Hence, he was excluded from the study. Thus in total, 75 patients met the inclusion criteria and completed the study. The baseline characteristics of the study participants are presented in Table 1.

The ET-Sevo concentration to maintain a bispectral index of 40-60 was lower in the Lignocaine group 
Table 1 Baseline demographics

\begin{tabular}{llll}
\hline & $\begin{array}{l}\text { Lignocaine } \\
(\mathbf{n = 3 7 )}\end{array}$ & $\begin{array}{l}\text { Saline } \\
(\mathbf{n = 3 8 )}\end{array}$ & p value \\
\hline Age (years) & $61(6.3)$ & $60(7.6)$ & 0.38 \\
Weight $(\mathrm{kg})$ & $85(14.1)$ & $83(11.9)$ & 0.43 \\
Body mass index $\left(\mathrm{kg} / \mathrm{m}^{2}\right)$ & $28(5.05)$ & $26(3.53)$ & 0.80 \\
ASA class & & & \\
I & $24(65 \%)$ & $26(68 \%)$ & 0.74 \\
॥ & $13(35 \%)$ & $12(32 \%)$ & 0.74 \\
III & 0 & 0 & \\
Gleason scores & $7(0.86)$ & $7(0.62)$ & 0.91 \\
PSA (ng/mL) & $8.7(5.02)$ & $7(4.85)$ & 0.54 \\
Co-morbidities & $15(40.5 \%)$ & $12(31.6 \%)$ & 0.42 \\
Hypertension & $10(27.0 \%)$ & $9(23.7 \%)$ & 0.74 \\
Diabetes & $1(2.6 \%)$ & $3(7.9 \%)$ & 0.32 \\
Peripheral vascular disease & $1(2.6 \%)$ & 0 & 0.31 \\
Chronic obstructive pulmonary & $1(2.6 \%)$ & 0 & 0.31 \\
$\quad$ disease & & & \\
Ischaemic heart disease & 0 & 0 & \\
Renal impairment & 0 & 0 & \\
Duration of surgery & $155.7 \mathrm{~min}$ & $141.6 \mathrm{~min}$ & 0.13 \\
\hline
\end{tabular}

Values are mean (SD) and number (proportion)

compared to the Saline group [1.49\% (SD: 0.32) vs. $1.89 \%$ (SD: 0.29 ); $95 \%$ CI 0.26 to $0.5, \mathrm{p}<0.001$ ] (Fig. 1). The average bispectral index in the Lignocaine group was 43.4 (SD: 6.0) vs. 49.8 (SD: 8.2) in the Saline group (p < 0.001) (Fig. 1). The average blood pressures throughout surgery, together with highest, mean, and lowest heart rates are summarised in Table 2. The highest, mean, and lowest intraoperative blood pressures are presented in Fig. 2.

In total, the Lignocaine group required more crystalloids than those in the Saline group [3281.1 mL (SD: 1094.6) vs. $2552.6 \mathrm{~mL}$ (SD: 1173.5); $\mathrm{p}=0.007$ ]. Hartmann's solution, which was the most used crystalloid, was administered in higher volumes in the Lignocaine group than in the saline group [3167.6 mL (SD: 1048.6) vs. $2281.6 \mathrm{~mL}$ (SD: 2281.6); $\mathrm{p}<0.001$ ). Gelofusine was the most used colloid and administered in similar amounts in both groups [530.6 mL (SD: 707.1) in the Lignocaine group vs. $500.0 \mathrm{~mL}$ (SD: 687.7 ); $\mathrm{p}=0.6$ ]. There were no significant differences in the amounts of albumen administered [112.9 mL (SD: 297.1) in the Lignocaine group vs. $126.3 \mathrm{~mL}$ (SD: 295.6); $\mathrm{p}<0.65$ ]. In the Lignocaine group, twenty-two patients (59\%) required either intermittent boluses of either metaraminol or ephedrine compared to fifteen patients $(39 \%)$ in the Saline group $(p=0.1)$. The median (IQR) dose of metaraminol in the Lignocaine group was $3 \mathrm{mg}(2.8: 4)$ vs. $3 \mathrm{mg}$ (2:3) in the Saline group $(\mathrm{p}=0.18)$. The median dose of ephedrine in the Lignocaine group was $15 \mathrm{mg}(7.5: 15)$ vs. $9 \mathrm{mg}(6: 10)$ in the Saline group $(\mathrm{p}=0.27)$.

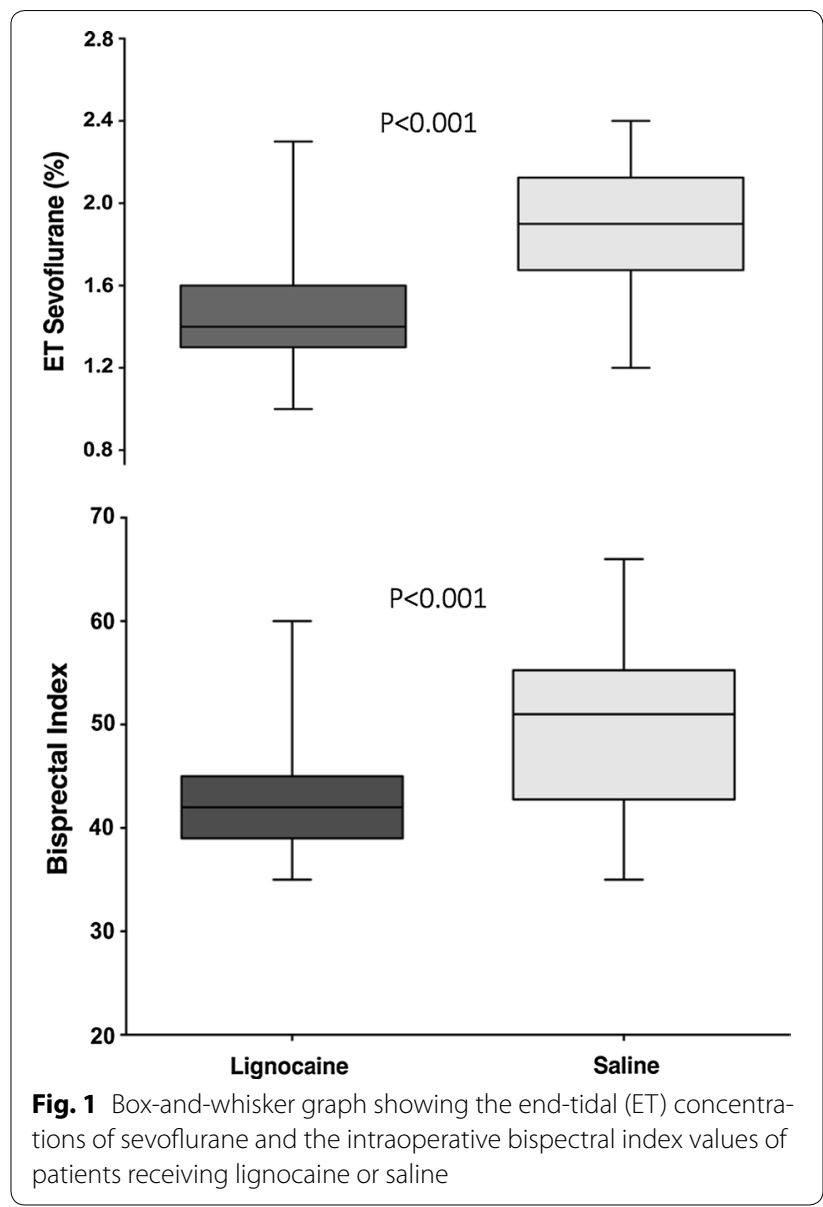

\section{Discussion}

In this analysis of a multicentre, double-blinded, randomised control trial [1], the administration of a bolus dose of IV lignocaine, followed by an IV infusion was associated with a decreased requirement of volatile anaesthetic agents, as compared to saline. The ET-Sevo concentration required to maintain anaesthesia was reduced by $21 \%$, and intraoperative systolic and mean arterial pressure and heart rate were significantly lower in the Lignocaine group. Whilst there is a growing body of evidence supporting the use of IV lignocaine in accelerating rehabilitation and improving outcomes after abdominal surgery [6-8], the present study shows that the intraoperative use of lignocaine also effects intraoperative haemodynamics and reduces the concentration of volatile agents required to maintain anaesthesia. These are important clinical implications for the optimal and safe provision of anaesthesia.

A recent systematic review (37 trials, 1429 patients) reported that IV lignocaine consistently attenuates cardiovascular response to laryngoscopy and tracheal intubation [11], however there are very few clinical studies that 
Table 2 Intraoperative haemodynamics

\begin{tabular}{|c|c|c|c|c|}
\hline & $\begin{array}{l}\text { Lignocaine } \\
(\mathrm{n}=37)\end{array}$ & $\begin{array}{l}\text { Saline } \\
(n=38)\end{array}$ & $95 \% \mathrm{Cl}$ & $\mathrm{p}$ value \\
\hline \multicolumn{5}{|l|}{ Average blood pressure $(\mathrm{mmHg})$} \\
\hline Systolic & $121.7(6.1)$ & $128.0(6.4)$ & 3.5 to 9.2 & $<0.001$ \\
\hline Diastolic & $70.2(6.7)$ & $72.1(6.2)$ & -1.1 to 4.9 & 0.2 \\
\hline Mean & $80.3(4.9)$ & $85.1(5.4)$ & -1.1 to 4.9 & 0.2 \\
\hline \multicolumn{5}{|l|}{ Heart rate (beats/min) } \\
\hline Highest & $97.5(7.1)$ & $103.8(9.7)$ & 2.4 to 10.3 & $<0.001$ \\
\hline Lowest & $52.1(7.7)$ & $59.0(7.4)$ & 3.3 to 10.3 & $<0.001$ \\
\hline Mean & $74.9(1.8)$ & $81.5(1.7)$ & 4.1 to 9.1 & $<0.001$ \\
\hline Number of patients requiring vasopressor use (ephedrine or metaraminol) & $22(59 \%)$ & $15(39 \%)$ & -26.5 to 42.6 & 0.1 \\
\hline Intraoperative temperature $\left({ }^{\circ} \mathrm{C}\right)$ & $35.5(0.5)$ & $35.6(0.5)$ & -0.34 to 0.14 & 0.41 \\
\hline Average bispectral index (\%) & $43.4(6.0)$ & $49.8(8.3)$ & 0.34 to 0.14 & 0.13 \\
\hline
\end{tabular}

Values are mean (SD) and number (proportion)

have methodically evaluated the intraoperative effects of systemically administered lignocaine on haemodynamics, volatile agent requirements, and the depth of anaesthesia. The use of IV lignocaine has been shown to be associated with a reduced requirement of intravenous anaesthetic agents, specifically propofol [12-15]. Intravenous lignocaine has also been shown to reduce the requirements of volatile anaesthetics in patients undergoing non-abdominal surgeries [16-18], findings similar to the present study. Interestingly, even the delivery of lignocaine via both the epidural and IV routes has been shown to reduce requirement of volatile anaesthetics
$[19,20]$. In laparoscopic abdominal surgery, IV lignocaine has reduced the average concentration of volatile anaesthetic agents by more than $35 \%$ [21, 22]. However, to our knowledge, in the context of major open abdominal surgery only two studies have evaluated the effects of IV lignocaine on the concentration of volatile anaesthetic required to maintain anaesthesia $[16,20]$. Hamp et al. found that the mean alveolar concentration of sevoflurane was $12 \%$ lower in those receiving a bolus dose of $1.5 \mathrm{mg} / \mathrm{kg}$ of intravenous lignocaine [13, 16]. Kuo et al. administered $2 \mathrm{mg} / \mathrm{kg}$ bolus of IV lignocaine followed by an infusion of intravenous lignocaine $(3 \mathrm{mg} / \mathrm{kg} / \mathrm{h})$, and

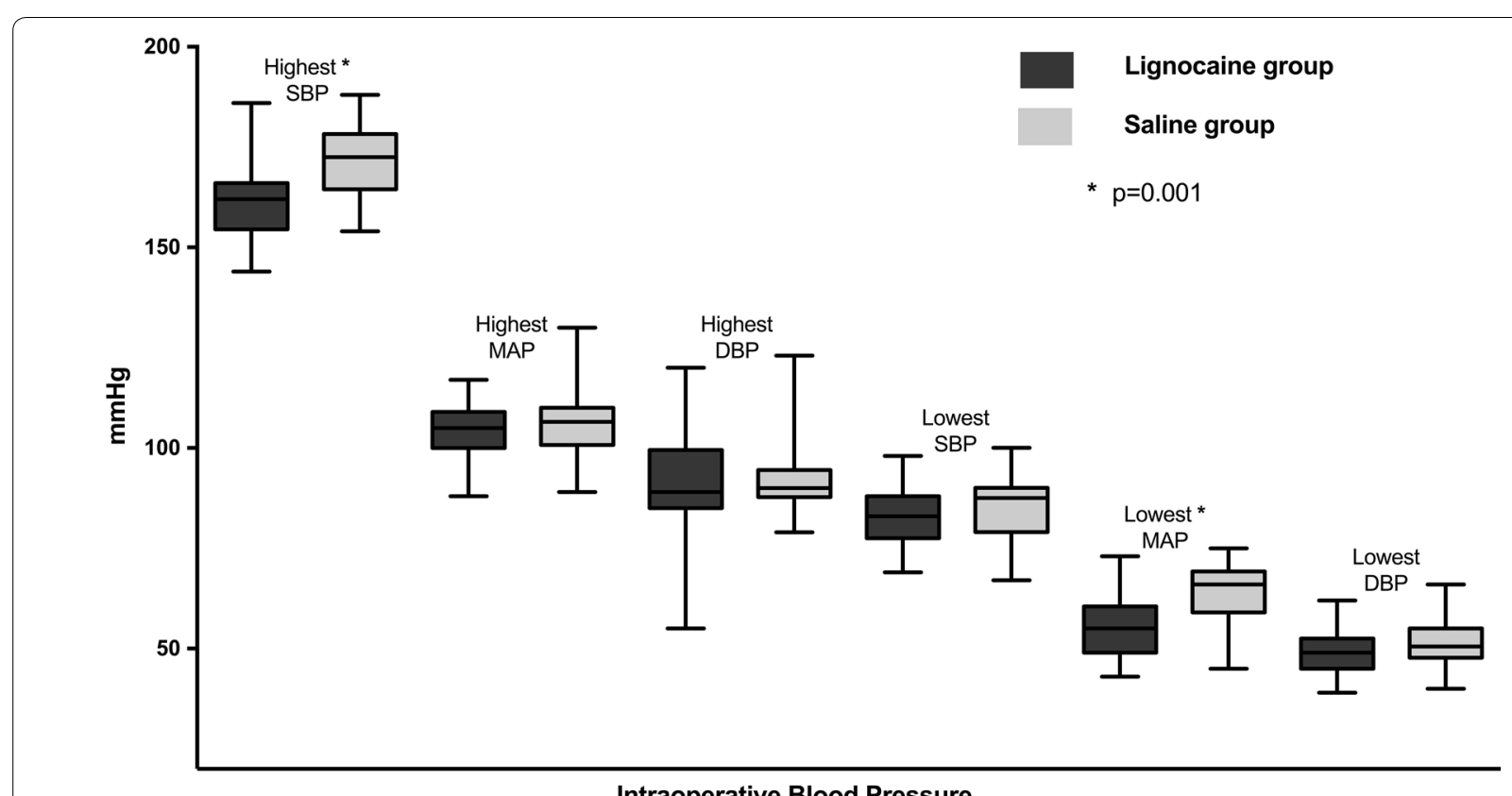

Intraoperative Blood Pressure

Fig. 2 Box-and-whisker graph showing the highest and lowest systolic (SBP), mean (MAP) and diastolic (DBP) blood pressures during surgery 


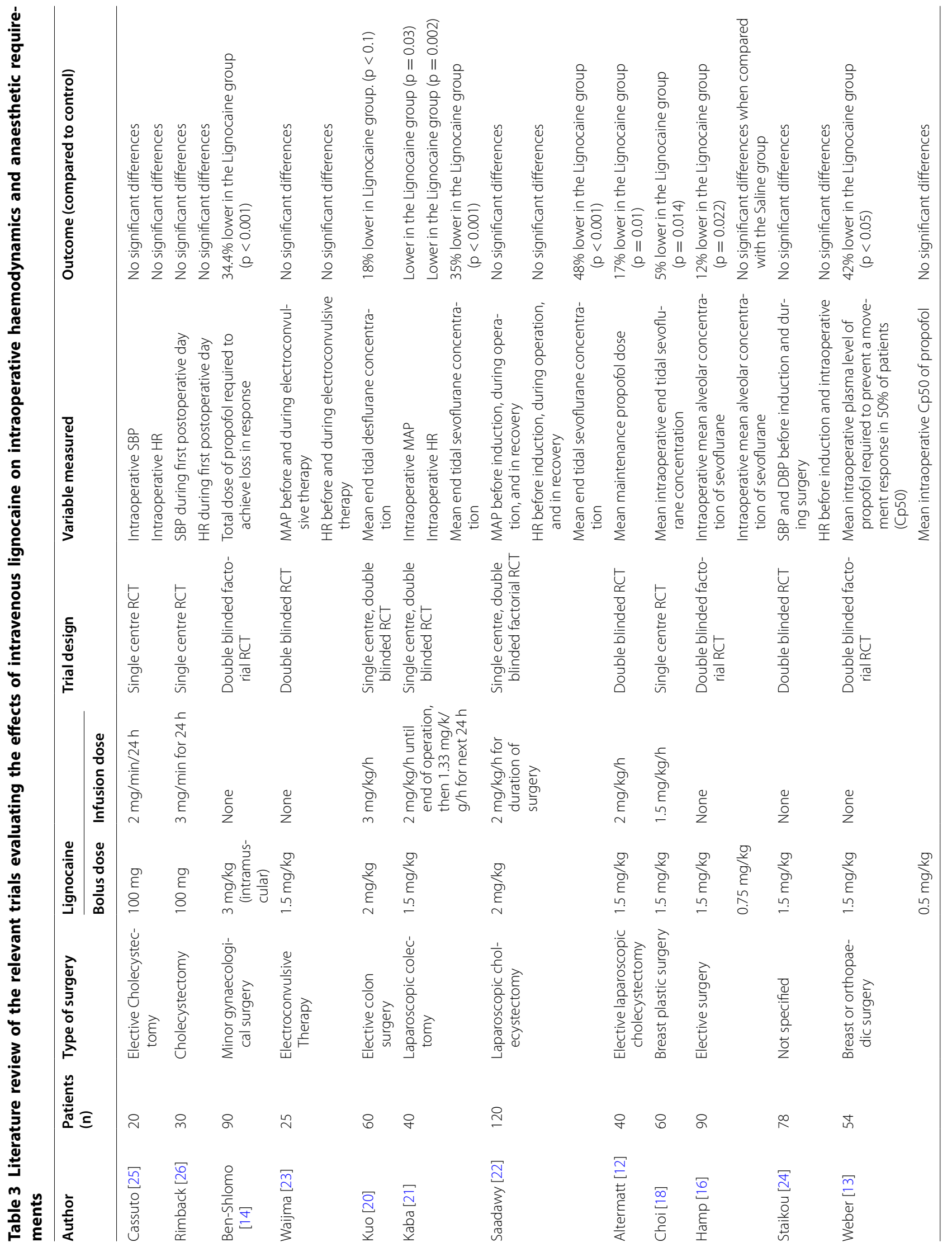


reported that the mean ET-Sevo concentration was 18\% lower in the Lignocaine group [20]. Unlike our study, neither of these trials reported any haemodynamic effects or cardiovascular changes with lignocaine. Furthermore, these studies are limited by the heterogeneity of the types of surgical procedures performed.

Paradoxically in our study, despite lower end-tidal concentrations of sevoflurane used to achieve $1 \mathrm{MAC}$ of anaesthesia in the Lignocaine group, BIS values were significantly lower, a finding that reflects a greater depth of anaesthesia; this may explain the significantly lower blood pressures and heart rates observed in the Lignocaine group. In addition, this may further explain why participants in the Lignocaine group required higher volumes of intraoperative fluids, and why a greater proportion of participants required vasoactive medications to support blood pressure. Anaesthetists should be mindful of these haemodynamic effects, which are not commonly reported in many of the clinical studies evaluating lignocaine in the perioperative setting. Numerous trials have evaluated the effects of IV lignocaine on intraoperative haemodynamics and anaesthetic requirement [12-14, 16, 18, 20-26] (Table 3). Noteworthy, some of these studies were performed in small sample of patients [26-28], whilst others failed to investigate the effects of combining a loading dose of lignocaine with a continuous infusion [24, 27]. Our findings of lower end tidal concentrations of volatile agents in the Lignocaine group provide support for the inclusion of lignocaine in the combination of pharmacological agents that may contribute to "balanced anaesthesia". Furthermore, it might also be feasible to use an infusion of lignocaine to attenuate the haemodynamic changes associated with open abdominal surgery.

There are several strengths to this study. First, we have investigated the combination of an IV loading dose and a continuous infusion of lignocaine on intraoperative haemodynamics and volumes of fluids used, as well as the concentration of volatile agent required to maintain anaesthesia. Second, we analysed data from a multi-centre study conducted in two teaching hospitals, providing some external validity and generalisability to other tertiary hospitals in developed countries. Third, the original trial was conducted under strict methodology, which minimises the risk of bias. Fourth, ex post facto calculation, when considering the concentration of volatile to maintain BIS value between 40 and 60 , showed that a sample size of least 38 patients per group would be necessary to detect a clinically relevant $0.4 \%$ difference in ET-Sevo concentration, with a Type 1 error of 0.05 and a statistical power of $90 \%$. The sample size in the present study is therefore completely consistent with this clinically important difference.
Our study however, does have several limitations. First, and most importantly our results may be considered less valid as the original trial [1], which was powered to evaluate length of hospital stay. Second, the original trial investigated generally healthy patients undergoing elective open radical prostatectomy. The results may not be applicable in patients with underlying comorbidities, including obesity or those undergoing emergency or other types of surgeries. Third, our study delivered a loading dose of $1.5 / \mathrm{mg} / \mathrm{kg}$ of IV lignocaine followed by $1.5 \mathrm{mg} / \mathrm{kg} / \mathrm{h}$ infusion for a $24-\mathrm{h}$ period. Our results may not be replicated when different doses of administration are used. Fourth, our study recorded the average haemodynamics and the ET-Sevo concentration taken throughout the operation. Our results may not be extrapolated to compare the efficacy of adjuvant lignocaine to given stimuli at specific points in time e.g. endotracheal intubation or surgical incision.

\section{Conclusions}

In conclusion, despite methodological limitations of the study, we have found that a loading dose of IV lignocaine followed by an intraoperative infusion significantly reduces the ET-Sevo concentration required to maintain anaesthesia during open radical prostatectomy. Further, this regimen was associated lower BIS values, and lower blood pressures and heart rates compared to saline. More participants receiving IV lignocaine required vasoactive therapy support, and a higher volume of IV fluid therapy was administered. Our results provide additional information regarding the potential contributions of parenteral lignocaine to modern balanced anaesthesia.

\section{Abbreviations}

IV: intravenous; SD: standard deviation; BIS: bispectral index; Cl: confidence interval; MAC: minimum alveolar concentration; ASA: American Society of Anaesthesiologists; ET-sevo: end-tidal sevoflurane; SBP: systolic blood pressure; MAP: mean arterial pressure; DBP: diastolic blood pressure; RCT: randomised control trial; PSA: prostate-specific antigen; HR: heart rate.

\section{Authors' contributions}

LW conceived the design of the study, collected data, performed statistical analysis of results, coordinated, reviewed and drafted manuscript. JJ prepared the initial manuscript, conducted the literature review, performed statistical analysis of results, reviewed and drafted the manuscript. CT, RH assisted with the study design, collected data, drafted and reviewed the manuscript. LM assisted with the study design, drafted and reviewed the manuscript. All authors read and reviewed the final manuscript.

\footnotetext{
Author details

${ }^{1}$ Department of Surgery, The University of Melbourne, Austin Health, VIC, Australia. ${ }^{2}$ Department of Anaesthesia, Austin Health, Heidelberg, VIC, Australia.

${ }^{3}$ Faculty of Medicine, The University of New South Wales, Sydney, Australia.

${ }^{4}$ Department of Anaesthesia, Eastern Health, Box Hill, VIC, Australia.
}

\section{Acknowledgements}

None. 


\section{Competing interests}

The authors declare that they have no competing interests.

\section{Availability of data and materials}

The datasets analysed during the current study are available from the corresponding author on reasonable request.

\section{Consent to publish}

All participants provided written informed consent to publish data from the original study.

\section{Ethics approval and consent to participate}

The original study [1] was approved by Human Research Ethics Units at Austin and Box Hill hospitals. All participants provided written consent for the primary study. The Ethics Committee approved the data collection of all the variables reported in this secondary analysis and participant consent was not obtained.

\section{Funding}

This study received a Pfizer Australian and New Zealand College of Anaesthetists Research Fellow Grant.

\section{Publisher's Note}

Springer Nature remains neutral with regard to jurisdictional claims in published maps and institutional affiliations.

Received: 8 February 2016 Accepted: 26 June 2017

Published online: 06 July 2017

\section{References}

1. Weinberg L, Rachbuch C, Ting S, Howard W, Yeomans M, Gordon I, et al. A randomised controlled trial of peri-operative lidocaine infusions for open radical prostatectomy. Anaesthesia. 2016;71:405-10.

2. Wilson J, Doherty TJ, Egger CM, Fidler A, Cox S, Rohrbach B. Effects of intravenous lidocaine, ketamine and the combination on the minimum alveolar concentration of sevoflurane in dogs. Vet Anaesth Analg. 2008:35:289-96.

3. Columbano N, Secci F, Careddu GM, Sotgiu G, Rossi G, Driessen B. Effects of lidocaine constant rate infusion on sevoflurane requirement, autonomic responses and postoperative analgesia in dogs undergoing ovariectomy under opioid-based balanced anaesthesia. Vet J. 2012;193:448-55.

4. Rezende ML, Wagner AE, Mama KR, Ferreira TH, Steffey EP. Effects of intravenous administration of lidocaine on the minimum alveolar concentration of sevoflurane in horses. Am J Vet Res. 2011:72:446-51.

5. Acevedo-Arcique CM, Ibancovichi JA, Chavez JR, Gutierrez-Blanco E, Moran-Muñoz R, Victoria-Mora JM, et al. Lidocaine, dexmedetomidine and their combination reduce isoflurane minimum alveolar concentration in dogs. PLoS ONE. 2014;9(9):e106620. doi:10.1371/journal. pone. 0106620 .

6. Kranke P, Jokinen J, Pace NL, Schnabel A, Hollmann MW, Hahnenkamp K, Eberhart LH, Poepping DM, Weibel S. Continuous intravenous perioperative lidocaine infusion for postoperative pain and recovery. Cochrane Database Syst Rev. 2015;16(7):CD009642. doi:10.1002/14651858. CD009642.pub2.

7. Marret E, Rolin M, Beaussier M, Bonnet F. Meta-analysis of intravenous lidocaine and postoperative recovery after abdominal surgery. Br I Surg. 2008:95:1331-8

8. Vigneault L, Turgeon AF, Cote D, Lauzier F, Zarychanski R, Moore L, et al. Perioperative intravenous lidocaine infusion for postoperative pain control: a meta-analysis of randomized controlled trials. Can J Anaesth. 2011:58:22-37.

9. Blood Management Guidelines: Module 2 Perioperative. National Blood Authority. 2012. http://www.nba.gov.au/guidelines/module2/po-mod2. pdf2. Accessed 2 Feb 2016.
10. Newcombe RG. Interval estimation for the difference between independent proportions: comparison of eleven methods. Stat Med. 1998;17:873-90.

11. Qi DY, Wang K, Zhang H, Du BX, Xu FY, Wang L, Zou Z, Shi XY. Efficacy of intravenous lidocaine versus placebo on attenuating cardiovascular response to laryngoscopy and tracheal intubation: a systematic review of randomized controlled trials. Minerva Anestesiol. 2013;79:1423-35.

12. Altermatt FR, Bugedo DA, Delfino AE, Solari S, Guerra I, Munoz HR, et al. Evaluation of the effect of intravenous lidocaine on propofol requirements during total intravenous anaesthesia as measured by bispectral index. Br J Anaesth. 2012;108:979-83.

13. Weber U, Krammel M, Linke S, Hamp T, Stimpfi T, Reiter B, et al. Intravenous lidocaine increases the depth of anaesthesia of propofol for skin incision - a randomised controlled trial. Acta Anaesthesiol Scand. 2015;59:310-8.

14. Ben-Shlomo I, Tverskoy M, Fleyshman G, Cherniavsky G. Hypnotic effects of i.v. propofol is enhanced by i.m. administration of either lignocaine or bupivacaine. Br J Anaesth. 1997:78:375-7.

15. Hans GA, Lauwick SM, Kaba A, Bonhomme V, Struys MM, Hans PC, et al. Intravenous lidocaine infusion reduces bispectral index-guided requirements of propofol only during surgical stimulation. $\mathrm{Br} J$ Anaesth. 2010:105:471-9.

16. Hamp T, Krammel M, Weber U, Schmid R, Graf A, Plöchl W. The effect of a bolus dose of intravenous lidocaine on the minimum alveolar concentration of sevoflurane: a prospective, randomized, double-blinded, placebocontrolled trial. Anesth Analg. 2013;117:323-8.

17. Himes RS Jr, Difazio CA, Burney RG. Effects of lidocaine on the anesthetic requirements for nitrous oxide and halothane. Anesthesiology. 1977:47:437-40.

18. Choi SJ, Kim MH, Jeong HY, Lee JJ. Effect of intraoperative lidocaine on anesthetic consumption, and bowel function, pain intensity, analgesic consumption and hospital stay after breast surgery. Korean J Anesthesiol. 2012:62:429-34.

19. Hodgson PS, Liu SS. Epidural lidocaine decreases sevoflurane requirement for adequate depth of anesthesia as measured by the bispectral index monitor. Anaesthesiology. 2001;94:799-803.

20. Kuo C, Jao S, Chen K, Wong CS, Yeh CC, Sheen MJ, et al. Comparison of the effects of thoracic epidural analgesia and i.v. infusion with lidocaine on cytokine response, postoperative pain and bowel function in patients. Br J Anaesth. 2006;97:640-6.

21. Kaba A, Laurent SR, Detroz BJ, Sessler DI, Durieux ME, Larny ML, et al. Intravenous lidocaine infusion facilitates acute rehabilitation after laparoscopic colectomy. Anesthesiology. 2007;106:11-8.

22. Saadawy IM, Kaki AM, Abd El Latif AA, Abd-Elmaksoud AM, Tolba OM Lidocaine vs. magnesium: effect on analgesia after laparoscopic cholecystectomy. Acta Anaesthesiol Scand. 2010;54:549-56.

23. Wajima Z, Yoshikawa T, Ogura A, Shiga T, Inoue T, Ogawa R. The effectiveness of intravenous lignocaine on haemodynamics and seizure duration during electroconvulsive therapy. Anaesth Intensive Care. 2002;30:742-6.

24. Staikou C, Paraskeva A, Karmaniolou I, Vezakis A, Tsaroucha A. Intravenous lidocaine does not affect the anesthetic depth during rapid sequence induction and intubation as assessed by Bispectral Index monitoring: a randomized double blind study. Arch Med Sci. 2013;9:713-8.

25. Cassuto J, Wallin G, Hogstrom S, Faxen A, Rimback G. Inhibition of postoperative pain by continuous low-dose intravenous infusion of lidocaine. Anesth Analg. 1985;64:971-4.

26. Rimback G, Cassuto J, Tollesson P. Treatment of postoperative paralytic ileus by intravenous lidocaine infusion. Anesth Analg. 1990;70:414-9.

27. Kim WY, Lee YS, Ok SJ, Chang MS, Kim JH, Park YC, Lim HJ. Lidocaine does not prevent bispectral index increase in response to endotracheal intubation. Anesth Analg. 2006;102:156-9.

28. Wallin G, Cassuto J, Högström S, Lindén I, Faxén A, Rimbäck G, et al. Effects of lidocaine infusion on the sympathetic response to abdominal surgery. Anesth Analg. 1987:66:1008-13. 